\title{
Lettres à Sophie. Lettres sur la Religion, sur l'âme humaine et sur l'existence de Dieu, édition critique par Olivier Bloch
}

\section{Paola Sosso}

\section{(2) OpenEdition}

Journals

\section{Edizione digitale}

URL: http://journals.openedition.org/studifrancesi/34682

DOI: $10.4000 /$ studifrancesi.34682

ISSN: 2421-5856

\section{Editore}

Rosenberg \& Sellier

\section{Edizione cartacea}

Data di pubblicazione: 1 novembre 2005

Paginazione: 416

ISSN: 0039-2944

\section{Notizia bibliografica digitale}

Paola Sosso, «Lettres à Sophie. Lettres sur la Religion, sur l'âme humaine et sur l'existence de Dieu, édition critique par Olivier Bloch», Studi Francesi [Online], 146 (XLIX | II) | 2005, online dal 30 novembre 2015, consultato il 19 avril 2021. URL: http://journals.openedition.org/studifrancesi/34682 ; DOI: https://doi.org/10.4000/studifrancesi.34682

Questo documento è stato generato automaticamente il 19 avril 2021.

\section{cc) (†) $\odot$}

Studi Francesi è distribuita con Licenza Creative Commons Attribuzione - Non commerciale - Non opere derivate 4.0 Internazionale. 


\title{
Lettres à Sophie. Lettres sur la Religion, sur l'âme humaine et sur l'existence de Dieu, édition critique par Olivier Bloch
}

\author{
Paola Sosso
}

\section{NOTIZIA}

Lettres à Sophie. Lettres sur la Religion, sur l'âme humaine et sur l'existence de Dieu, édition critique par Olivier BLocH, Paris, Champion, 2004 («Libre pensée et littérature clandestine»), pp. 310.

1 «Avez-vous-vu les Lettres à Sophie»: questa domanda, che si trova in una lettera datata 10 luglio 1770 del chevalier Redmond, è il solo elemento che permette di collocare con certezza la pubblicazione dell'opera nella prima metà del 1770. Opera tardiva, appartenente senza dubbio alla «libre pensée» e alla letteratura filosofica clandestina del Secolo dei Lumi, questo testo offre una serie di ventun lettere fittizie, inviate da un uomo a una ex-amante per illuminarla riguardo alla falsità dei pregiudizi religiosi. Si tratta di un'opera anonima di cui risulta praticamente impossibile, spiega il curatore dell'edizione critica, rintracciare l'autore, sicuramente un erudito bibliofilo d'origine protestante. Sul manoscritto, conservato alla Biblioteca Mazarine (cote 1183) e copiato sulla versione stampata, compare un altro titolo, Lettres sur la religion, sur l'âme humaine et sur l'existence de Dieu, ma il terzo punto non viene trattato nelle lettere, e certamente non era svolto in una sezione andata perduta, perché le lettere hanno chiaramente l'aspetto di un'opera incompiuta. Tra le due versioni, quella stampata e quella manoscritta, risultano di rilievo alcune varianti puntualmente segnalate dal curatore per il loro significato filosofico e storico. Le lettere vengono presentate e analizzate nella seconda parte dell'introduzione, che colloca il testo nella tradizione del libertinage dix-septièmiste e lo avvicina a tutta una serie di scritti critici, eterodossi e anticristiani 
che vanno da Bayle a Voltaire passando attraverso opere clandestine per lo più anonime. Precisa e dettagliata anche la ricerca delle fonti utilizzate, che mette in luce la tattica del «montrer-cacher» da parte dell'anonimo autore: il ricorso ai modelli di opere anticristiane, atee e materialiste, più o meno note, della letteratura filosofica del XVII (assenti, salvo rare eccezioni, i philosophes del XVIII secolo), avviene all'interno di una struttura e di uno stile bizzarri, che sfiorano talvolta la caricatura e l'ironia (dislocazione delle citazioni, argomentazioni grottesche, collages e parodie, dimostrazioni inconcludenti, conclusioni posticce...). Opera enigmatica, poco nota e poco diffusa tra i contemporanei, le Lettres à Sophie inseriscono il chiaro orientamento materialista all'interno della cultura protestante, attestata principalmente dal ricorso frequente ad alcune fonti (principalmente Joseph Addison, De la religion chrétienne, tradotto da Gabriel Seigneux de Corrévon, Losanna, 1757), dall'uso di traduzioni protestanti delle sacre Scritture e dalla critica ricorrente del culto dei santi e della Chiesa romana. La data di pubblicazione, i riferimenti, i giochi intellettuali e l'incompiutezza del testo sembrano indicare, come suggerisce il curatore, il coronamento e il declino di un genere, destinato tuttavia a riemergere dall'ombra a fine secolo grazie all'utilizzo che ne farà Sade Della Nouvelle Justine (1799). Le note dell'autore e quelle dell'editore compaiono alla fine del testo; il volume è corredato da un apparato bibliografico e dall'indice dei nomi. 